\title{
Is There a Need for Intrinsic Values in Conservation Biology?
}

\author{
Dominic Hyde
}

University of Queensland

In one of the first papers ever published in (what was to become) the field of environmental philosophy, nearly half a century ago, Richard Routley ${ }^{1}$ (working in close partnership with Val Routley) claimed that there was a need for a new, an environmental, ethic to properly underpin "people's relationship to the natural environment". ${ }^{2}$ Richard and Val went on to develop an environmental ethic that they claimed differed from the traditional Western "super ethic" in recognising that items other than humans were intrinsically valuable. And that, therefore, we must move beyond the inherent "human chauvinism" of the traditional position in our determinations of what is good and permissible, to a view that treats some nonhumans as more than mere means to human ends. ${ }^{3}$ Over the ensuing decades Richard continued to defend and articulate his position, which he termed "deep green theory" - distinguishing it from "deep ecology" with which it was sometimes conflated. He saw his axiological theory as crucial not only to an adequate account of value and environmental justice, but also to the development of a human culture capable of sustaining itself into the future. As time went on he saw the lack of interest in a new ethic in increasingly dismal terms, concerned in his final years that "philosophers fiddle while the Earth begin to burn". ${ }^{4}$ Given all this, then, he may have taken some satisfaction in seeing the apparent growth of this new ethical awareness in conservation planning, with increasing calls by

\footnotetext{
${ }^{1}$ Richard later changed his name to 'Sylvan', Val later changed hers to 'Plumwood'.

${ }^{2}$ See Routley (1973). The other paper that made up the first published research in the field, appearing at almost exactly the same time, was Naess (1973). Arne Naess and Richard were to continue working at close quarters until Richard's death in 1996. Naess was advocating a radical new ethic similar in some ways to Richard and Val, though they were later to distance themselves from his "deep ecology".

${ }^{3}$ See Routley and Routley (1979).

${ }^{4}$ Sylvan (1996), Prologue.
}

Australasian Journal of Logic (15:2) 2018, Article no. 4.1 
conservation biologists like Soulé (1985), Noss and Cooperrider (1994), and McCauley (2006) for the recognition of the intrinsic value of elements of the natural environment.

However, recent arguments have emerged that push back against these calls, claiming that there is, in fact, no need for this development of value theory in conservation planning - the orthodoxy that Richard was desperate to overthrow is said to be correct. Maguire and Justus (2008) and Justus et al. (2009) argue that the appeal to intrinsic value lacks sufficient clarity and fails to serve the needs of decision-making in conservation biology. These criticisms target problems in the use of the concept of intrinsic value by conservation biologists and serve to highlight confusion and difficulties in the development of a coherent and efficacious theory of intrinsic value for application in conservation decision-making. However, I shall argue contra these critics that they do not count as sufficient grounds for the rejection of such a theory, but rather serve to show how such a theory should properly be understood. The debate here is thus instructive in clearing away some of the misguided claims frequently encountered in this area. Richard's theoretical account of the nature of and need for intrinsic value in the natural world is required more than ever in conservation biology, and we are well-served by returning to his original accounts to correct errors that have crept into recent debate in the area.

\section{Conservation based on intrinsic value?}

Many conservationists have argued for the improved protection of natural entities through appeal to intrinsic value. What then is intrinsic value and why appeal to it?

Following Routley and Routley (1980) - themselves following Moore's (1903) original use of the notion ${ }^{5}$ - the intrinsic value of something is the value that it has "non-instrumentally", value that resides in the fact that it should be valued "for itself" - value that is "not reducible (in any way) to human interests" 8 or perceived human advantage - as opposed to value that it might have as a "means to our end" (as Moore put it). So those who advocate the intrinsic value of nonhuman biota as an improved basis for conservation are to be understood as advocating conserva-

\footnotetext{
${ }^{5} \mathrm{Cf}$. Moore (1903), sections 15, 18 and 50. (Thanks to Roger Lamb for these references.) ${ }^{6}$ p. 126.

${ }^{7}$ p. 131.

${ }^{8}$ p. 129.
}

Australasian Journal of Logic (15:2) 2018 Article no. 4.1 
tion that pays due attention to their value, value considered as independent from (i.e. not reducible in any way to) human ends or interests. ${ }^{9}$ Why might intrinsic value theorists make such a recommendation? Well, broadly put, they are concerned that conservation that only pays attention to the value nonhuman biota have for humans (as opposed to value they may have for their own sake, "inherently") - i.e. conservation that only pays attention to the instrumental value of nonhuman biota, its value as a means to human advantage - will result in decision-making where human interests are paramount since the value of any nonhuman entity will ultimately come down to the value that thing has for us; all nonhuman value will be a matter of the value a thing has for our sake. And this domination of human interests is little better than the domination of self-interest; it neglects the value that other things might have independently of our interests. Human-centeredness (what Routley and Routley (1980) termed "human chauvinism") is little better than self-centeredness, and is to be overcome by acknowledging that, whether or not humans are the ultimate source of value, they are not the ultimate or only locus of value. ${ }^{10}$ Nonhuman biota may have value or be valued for their own sake, as ends in themselves, regardless of whether or not they have value for us, that is, regardless of whether we instrumentally value them. Such value is described as intrinsic value.

The first thing to note here is that those advocating intrinsic value in the nonhuman world, those advocating what Routley (1973) calls an environmental ethic, are not advocating a new, further kind of value. As Aristotle pointed out, any appeal to value must ultimately appeal to intrinsic value at some point, on pain of infinite regress. Any explanation of the instrumental value of a thing must eventually be grounded in intrinsic value somewhere. If something is instrumentally valuable, so valuable for something else, as a means to something else's ends, then its value must derive from the value of that other thing. If the value of that other thing, in turn, derives its value from the value of something else then that third thing must itself be valuable. And so on. Unless the derivative value of things, the value they have for other things, can be grounded somewhere in the non-derivative value something has, value it has for its own sake, then vicious

\footnotetext{
${ }^{9}$ Curiously, Justus et al. (2009) complain that saying "an intrinsically valuable entity is valuable in itself or as an end in itself" is an "unhelpful allusion" (p. 187). On the contrary, as the standard definition it is not an allusion and is helpful in drawing the contrast with instrumental value.

${ }^{10}$ Routley and Routley (1979), section II, argues, at length, that the inference from values having their source in us as valuers to the conclusion that values are determined by human interests is an invalid one.
}

Australasian Journal of Logic (15:2) 2018 Article no. 4.1 
regress ensues and value is not grounded anywhere. Moreover, even if one is not persuaded that intrinsic value is required for instrumental value to make sense, it nonetheless seems obvious that people commit to the actual existence of intrinsic value - e.g. truth, pleasure, or some such. Approaching things from the opposite end of the spectrum, take the negative value of pain, for example. It seems obvious to many that it does not derive its disvalue by way of some further disvalue; it just is bad in itself. There is nothing new in the kind of value (positive or negative) being discussed.

Dominant ethical theories like traditional utilitarianism accommodate such value by attributing intrinsic value to humans by way of human states (or, more recently and more broadly, following Singer (1975), perhaps sentient creatures any creature capable of pleasure and pain). As a non-derivative value, this intrinsic value of humans can then explain the instrumental value of other things. Cows are (instrumentally) valuable because they provide us with meat and other products of value to us. The cows being valuable to us confers derivative value on them since they serve the interests of that which is nonderivately, intrinsically valuable, namely humans. Put differently, they serve a valuable end, us. This traditional human-centred account of value locates ultimate, intrinsic value in us. The human species is special in a way that the nonhuman is not; humans are intrinsically valuable and the nonhuman biota has merely instrumental value.

If accounts of value, then, already accept intrinsic value somewhere, what is at issue in the appeal to the intrinsic value of the nonhuman in conservation biology cannot be the existence of intrinsic value, but its extent. What is distinctive of an environmental ethic is that it simply seeks to extend intrinsic value to nonhumans, an extension argued for by way of, for example, the "last man example" (see Routley (1973) - though Routley did not, at the time, explicitly mention "intrinsic values"; this explanatory concept was first mentioned in Val's critical notice of Passmore's Man's Responsibility For Nature, Routley (1975), and later explicitly taken up as the distinctive feature of the "new ethic"). This extension fits a familiar pattern. History, arguably, contains many such extensions. The presumed intrinsic value of white Europeans over other people was all too often presupposed in attempts to legitimise slavery. Slaves were not intrinsically valuable (they weren't human, where 'human' denoted intrinsically valuable members of the species homo sapiens). The value of a slave was the value that could be derived from his or her usefulness to the (intrinsically valuable) dominant class. Such racial chauvinism, restricting intrinsic value to a preferred dominant class, is now generally rejected as unacceptable. So too gender chauvinism, according to which the derivative value of a woman was their value to men. Social justice 
debates are, in effect, riddled with criticism of unjustifiable restrictions on the extension of the set of bearers of intrinsic value. Social justice (for humans) demands the extension of intrinsic value to (potentially) all humans. Advocates of an environmental ethic go further, recommending its extension beyond the human to species, ecosystems and other nonhuman entities.

\section{What is wrong with the extension of intrinsic value?}

With this in mind, we might then ask whether the proposed extension of the locus of intrinsic value is coherent, and whether it is necessary for conservation. Maguire and Justus (2008) answer in the negative, targeting intrinsic value as a poor basis for conservation decision-making on two counts: "(1) intrinsic value is a vaguely formulated concept and not amenable to the sort of comparative expression as needed for conservation decision-making; and (2) instrumental value is a much richer concept than generally appreciated, permitting a full range of values of biota to be considered in conservation decisions". ${ }^{11}$ Let us turn, initially, to (1).

The first point worth making is that it cannot especially count against an environmental ethic (extending intrinsic value to nature) that the concept of intrinsic value itself is vague. Since it is invoked in any theory of value, any unclarity will infect value theory per se, and an environmental ethic is not particularly vulnerable in this respect. And it is hard to see why the extension of intrinsic value beyond the human should, as Maguire and Justus suggest, engender special problems for its use in decision-making. After all, we make value-decisions in the purely human realm (decisions based on considerations including the intrinsic value of the persons in question). For example, we make decisions between the delivery of healthcare to one person or another competing for this benefit and so are forced into making judgements involving things of intrinsic value - persons. Of course, they can be very difficult decisions to make, and we might sometimes appeal to a person's additional instrumental value as well, but we ought not conclude from this that the intrinsic value of the persons involved ought somehow be ignored or (worse) that they cannot usefully be thought of as having intrinsic value. It would be a gross misrepresentation of human value and human dignity to restrict our deliberations to the value that the respective persons have for others, as a means to their ends - a restriction to their derivative, non-intrinsic, merely instrumental value. Of course, as pointed out in Justus et al. (2009), questions remain as to precisely how intrinsic value might be distributed across the nonhuman world but

${ }^{11}$ Maguire and Justus (2008), p. 910.

Australasian Journal of Logic (15:2) 2018 Article no. 4.1 
these simply mirror the questions as to how such value is distributed across humans. Both individuals and groups, human and nonhuman, might have intrinsic value and saying why matters. But such accounts exist. (See, for example, Routley and Routley (1980), Elliot (1997).) Value assignments are contestable, but these issues are not particular to intrinsic value assignments in the natural, that is, nonhuman world.

Of course, problems may well attend particular ways of extending intrinsic value that preclude comparison of value. One notable extension, made by some in the field of conservation biology, and rightly of concern, is the claim that intrinsic value in nature is "priceless" or "infinite" - e.g. McCauley (2006). Both Maguire and Justus (2008) and Justus et al. (2009) are critical on these grounds. ${ }^{12}$ And they are right to be. As they point out, such an account of intrinsic value would entail the superior value of any intrinsically valuable item to all and any other items of merely finite value, and would preclude any nontrivial comparison of the relative values of different items of intrinsic value. All are infinitely valuable and so no outcome that ranks the protection of one intrinsically valuable item (a rare temperate rainforest, say) over that of another (a wombat, say) could be justified. Yet just such choices face conservationists and some nontrivial decision-procedure seems required. However, independently of any considerations arising from an environmental ethic, we can already see that claims that intrinsic value is priceless or infinite are misguided (and so should not be imported into debates that seek to extend intrinsic value to the nonhuman). To be sure, there are those that value (paradigmatically intrinsically valuable) humans as priceless. For example, it is sometimes said that "you cannot put a price on human life". But, of course, we can and do in the sense that we make value judgements that discriminate between (intrinsically valuable) humans. Since infinite value cannot underpin such a judgement, we learn that intrinsic value is not always (if ever) infinite. Surely there are situations where the saving of one hundred human lives is to be preferred over the saving of just one. If humans had infinite intrinsic value then the value of the hundred is no more nor less than that of the one, such is the mathematics of infinity.

One might object that, in fact, what is going on in the foregoing comparisons is that intrinsic value is being ignored altogether and such comparative judgements are being made on the basis of purely instrumental values, and, thus, so much the worse for the efficacy of intrinsic value in debates over value comparisons, and conservation decision-making in particular. Both Maguire and Justus (2008) and

${ }^{12}$ See Maguire and Justus (2008), p. 911; Justus et al. (2009), p. 189.

Australasian Journal of Logic (15:2) 2018 Article no. 4.1 
Justus et al. (2009) appear to be making just such claims. But the fact that we might calculate what a human life is "worth" (as Maguire and Justus put it, p. 910), and even express this in quantitative terms, does not preclude some costing of that thing's (or person's) intrinsic value in the calculation. Knowing what weight to give it is, of course, difficult (a problem I return to below), but we would hope and expect that more than their mere instrumental value to others was considered (e.g. through some appeal to their dignity or preference for a "good life"); i.e. we aim to include, however poorly, their intrinsic value. That this may need to be expressed in quantitative terms in a particular decision-theoretic framework does not preclude its inclusion. (Frequently, of course, it is sufficient to achieve a comparative ranking rather than a quantitative rating.)

And here we see the force of those advocating the recognition of the intrinsic value of nonhuman biota. What such an environmental ethics permits is the inclusion into value judgements of a thing's intrinsic value. Just as a person may have considerable instrumental value (being a good breadwinner for the family, etc.) but be valued as more than a mere means to others' ends, so too with the nonhuman. When judging whether or not to permit development in cassowary habitat, an environmental ethic claims that we should consider more than the cassowary's tourism value, or value in the maintenance of eco-system services (through forest regeneration, etc.), or other instrumental values - values that the cassowary has for us, values that advantage us. We ought also give some evaluative weight to the cassowary itself, for its own sake. Just as human actions are morally constrained by their effects on other humans, so too ought human actions be morally constrained by their effects on other nonhumans, and this is what the extension of the locus of intrinsic value aims to achieve.

This extension does not require the indiscriminate valuing of all things as equal (let alone, infinite) any more than the recognition of the intrinsic value of humans requires that we treat all humans as equally valuable. We can discriminate. Value, in particular intrinsic value, is not evenly spread across the class of humans, let alone across the broader class that includes nonhumans. Richard is very clear on this: "having irreducible value ... does not imply having equal irreducible value, anymore than having weight implies having equal weight." 13 Historically, some proposing a new ethic have, indeed, committed to the idea, among them some deep ecologists, and it is, perhaps, this influence at play in current debates. But Richard offers an alternative development of the new ethic that avoids this (and other problems that beset deep ecology) and is clear in his condemnation.

\footnotetext{
${ }^{13}$ Sylvan (1985), p. 7.
}

Australasian Journal of Logic (15:2) 2018 Article no. 4.1 
According to Naess, a biospheric egalitarian principle, of equal [intrinsic] value of all life, is "an intuitively clear and obvious value axiom", at least "to the ecological field-worker" (1973, p. 96). But empirical surveys would almost certainly not sustain Naess's claims. The principle seems generally neither intuitive nor obvious ... On the contrary, value seems, like yellowness, to be much more patchily distributed across the universe. Special places, for instance, are especially valuable ... even if every living thing were assigned value, it would not follow (in the way sometimes invalidly argued) that every thing has it equally. ${ }^{14}$

What we can already say then, irrespective of whether or not nonhuman items can have intrinsic value, is that accounts of intrinsic value as necessarily infinite, or otherwise everywhere equal, are mistaken. The biospheric egalitarianism of deep ecology imported into debates about intrinsic value in conservation biology ought be rejected. Even on a traditional human-centred account of intrinsic value, we already require an account of such value that permits non-trivial comparison. So, regardless of claims like those of McCauley (2006) - who have put forward a particular version of intrinsic value theory, apparently drawing on deep ecology, that is fraught with problems - there is no reason why intrinsic value should be seen as acknowledging the equal value of all species and ecosystems, or (even worse) valuing them as "priceless" or "infinite". To be sure, any intrinsic value theory that commits itself to these extraneous features is subject to damaging criticism, but this observation does not undermine the appeal to intrinsic value per se, it simply serves to show how not to understand the concept, and was not how the concept was understood by Richard. ${ }^{15}$

\section{Is intrinsic value 'valuer-independent'?}

There is a further, related charge associated with criticism (1) mentioned at the beginning of the previous section: that committing to the intrinsic value of natu-

\footnotetext{
${ }^{14}$ ibid.

${ }^{15}$ Not only did Richard reject the egalitarian principle of the equal intrinsic value of all life, he thought that value was unevenly distributed in such a way that sometimes the value of the nonhuman could trump the value of humans - i.e. he also rejected what he termed "the greater value assumption" according to which "even though other things may have intrinsic value, people or humans are more valuable than anything else, and rank more highly", Routley and Routley (1980), p. 171.
}

Australasian Journal of Logic (15:2) 2018 Article no. 4.1 
ral entities cannot guide the decision-making that conservation requires because it precludes conservation decisions being analysed with the same tools as other decisions with multiple, sometimes conflicting, goals; and this because we have no clear means to measure and weigh a thing's intrinsic value.

One might well wonder why comparisons of intrinsic value are taken to be so intractable. The answer seems to reside in the conception of "intrinsic value" under discussion. Justus et al. complain that "unlike instrumental value, characterizations of intrinsic value in the conservation literature suggest it is valuer independent and thus independent of stakeholder valuation. It therefore seems to have no role in these decision frameworks." 16 Thus, it appears that what underpins their concern is the suggestion that intrinsic value is valuer-independent. And the claim of valuer-independence is, indeed, one that has been applied to accounts of intrinsic value. Since its early explicit advocacy in environmental ethics in the 1970 s, the idea that intrinsic value is problematic since valuer-independent, and thus difficult to calculate, has surfaced again and again. ${ }^{17}$

What lies at the heart of such criticisms is the idea that intrinsic value is objective value, value that inheres in an object independently of any valuers, i.e. independently of whether the object is valued by valuers or not. As Sagoff (2009) suggests, Justus et al. react against just such a view of intrinsic value. They contrast intrinsic value with instrumental value, where entities "with instrumentally valuable properties are valuable to the extent they are or will be considered valuable by valuers". ${ }^{18}$ For example, "Art is instrumentally, not intrinsically, valuable because its value is dependent on and derives from the responses it produces in humans". ${ }^{19}$ Intrinsic value then is understood as precisely that kind of value that is not dependent on nor derives from the responses it produces in humans; entities with intrinsically valuable properties are valuable regardless of whether or not they are considered valuable by valuers.

Intrinsic value is thus valuer-independent and objective, on this view, in just the same way that it is commonly thought that the mass of an object is an objective property of the object in question. Now a problem emerges. Unlike an object's mass, which we can judge by way of our normal senses, an object's intrinsic value

\footnotetext{
${ }^{16}$ Justus et al. (2009), pp. 188-9.

${ }^{17}$ See, for example, an early response to the Routleys: Mannison (1980), p. 57. Richard and Val went to great pains to refute charges of objectivism commonly associated with intrinsic values - intrinsic values needn't be objective values, they argued (cf. Routley and Routley (1980), p. 154ff).

${ }^{18}$ Justus et al. (2009), pp. 187.

${ }^{19}$ Justus et al. (2009), pp. 188.
}

Australasian Journal of Logic (15:2) 2018 Article no. 4.1 
cannot in any obvious way be judged without positing some analogous sense capable of discerning value, some intuitive moral faculty. In this respect, an objectivist account of intrinsic value seems to suffer from an epistemological problem (how can we know the value weighting of such an object?) broadly similar to that faced by an objectivist account of abstract objects like numbers and sets. If such objects have objective existence, independently of us, then how can we explain our knowledge of truths involving them without recourse to some special mathematical intuition? This is the classic problem of epistemic access that is levelled at Platonist accounts of mathematics. So, too, with the value posited by intrinsic value theory. Moral intuitionism threatens. This supposed independence of intrinsic value from valuers results in its epistemological intractability.

But such an objection to the extension of intrinsic value to nonhuman biota is contentious. Firstly (repeating a point made earlier), whether or not intrinsic value is objective in this sense, we already have good evidence that it can be included in decision-making since we already reconcile (however badly) opposing intrinsic values in decision-making about humans (agreed by most, if not all, parties to the conservation debate to involve deliberation over competing intrinsic values). It is certainly true that weighing intrinsic value is difficult, but, as the Routleys point out,

the difficulties of transferring or adapting rather standard methods of assessment, such as decision theory and cost-benefit analyses, to provide rational decision methods in the case of environmental matters has been much exaggerated ... [A]n environmental ethic should not, any more than other ethics or economics, be expected to provide a decision procedure for any and every case that may arise: the theory (and accompanying intuitions) may have to be developed to resolve some cases, while other cases may go (cheerfully) undecided. On similar test or decision cases, e.g. one group of starving people versus another group in a situation of limited resources, or quality of life versus number of humans, conventional ethical theories may offer no quick, or clearcut, resolutions, etc. ${ }^{20}$

But these difficulties are not adequate grounds for the outright exclusion of intrinsic value from our deliberations.

Secondly, and more importantly, equating intrinsic value with objective value risks repeating an all-too common error. They are not synonymous. Values can be

${ }^{20}$ Routley and Routley (1980), p. 173.

Australasian Journal of Logic (15:2) 2018 Article no. 4.1 
intrinsic yet nonetheless non-objective. To put the point another way, it does not follow from the dependence of a value on human valuers (non-objectivity) that the value must be instrumental (non-intrinsic), and for many ethical theorists it is not thought to follow. (See, for example, a subjectivist account of intrinsic value in Elliot (1997). For a good summary of the issues here see Sandler (2012).) A problem arises from equivocation on the exact sense of 'independence' at issue. Values might be said to be independent of valuers insofar as things may be said to have value independently of their being valued by us, or they may be said to be independent of valuers insofar as things may be said to have value independently of their value for us. Non-objectivists about value (e.g. subjectivists) will agree that to have value requires valuers - for value to come into the world valuers are required in some way or other and value is, thus, not detached from valuers yet it does not follow from this that our valuations are human centred and that, accordingly, when we value things we must be judging their value for us. Even if values are, indeed, anthropogenic it does not follow that they are anthropocentric. Value might depend on (and, for the subjectivist, ultimately derive from) us in some way but valuations need not be ultimately concerned merely with what is valuable for us.

Of course, worries attend those non-objectivist accounts of value that are subjectivist, anthropogenic accounts. If values have their source in us then the value of a thing depends, problematically, on our valuing them. For this reason the objective nature of intrinsic value is appealing, securing the value of things against the vagaries of human valuers. The strong foundations sought by conservationists for the value of natural items might be taken to require an objectivist story to secure the necessary robustness of value, thus explaining the claimed prevalence of objectivist accounts of intrinsic value in the conservation literature, and therewith follow the attendant epistemic problems for their inclusion in decision theoretic frameworks. However, a conservationist's robust defence of nature through a robust account of the intrinsic value of (at least) some nonhuman entities need not commit them to an objectivist theory of value. Values may still depend on valuers without losing their robustness.

In this respect, values might be rather like colour or smell. Standard accounts of colour acknowledge that particular objects may be coloured at a time though at that time there is no one seeing them and, importantly, they have this robustness without denying that there is some kind of dependency of colour on suitable observers. To be red is for an object to be such that it would appear red to normal observers under normal conditions. On this response-dependent account, so-called secondary qualities like colour or smell can be said to be robust dis- 
positional properties of the things in question, determined by the responses of potential select observers to the things in themselves. So too, one might think, with values. Things may be valuable in the absence of anyone actually valuing them, while nonetheless depending on potential (select) valuers, potential valuers suitably informed (say). Natural entities might thus be valuable, whether or not there is anybody to do the actual valuing.

For the record, while likening intrinsic value to response-dependent properties like colour might help in illuminating the existence of at least one path between purely subjectivist accounts and objectivist ones, allowing for a robustness while admitting an essential connection to valuers ("no values without possible valuers"), this was not, ultimately, Richard's route. "Goodness, and value more generally ... are not secondary or tertiary or response dependent properties, and a comparison with shape is superior to one with colour" 21 - though he had earlier found the comparison useful. Nonetheless, he maintained his view that:

Values, of one sort or another, are features objects may have or lack; they are not subjective, they are not features which reduce to states or conditions of subjects or valuers. But no more are they objective features, natural or empirical features of objects, features entirely detached from valuers. A largely unquestioned false dichotomy between subjective and objective ethical theories has served to rule out important options. ${ }^{22}$

In the end then, there seems no reason why we cannot measure and weigh a thing's intrinsic value in just the same way we measure and weigh other values. There is nothing intrinsic to intrinsic values that puts them beyond measure; certainly, in measuring we do not thereby establish them as instrumental.

Of course, measuring and weighing value, whether instrumental or intrinsic is a fraught social enterprise and a neat consensus is rarely, if ever, achieved. But the introduction of intrinsically valuable nonhuman items does not, in itself, constitute an impassable barrier.

\section{Are intrinsic values needed?}

With a suitably robust non-objective account of value that is nonetheless not anthropocentric, extending intrinsic value to the nonhuman, it is instructive to fi-

\footnotetext{
${ }^{21}$ Sylvan and Bennett (1994), p. 143. (Thanks, again, to Roger Lamb for the reference.)

${ }^{22}$ Routley and Routley (1980), p. 154.
} 
nally turn to criticism (2) identified earlier as grounds for rejecting intrinsic value in conservation decision-making: namely, that intrinsic value is not needed once the full richness of the concept of instrumental value is appreciated, a concept which (Justus et al. claim) admits the full range of value considerations needed for conservation decisions.

Here we see potential equivocation of the kind identified a few paragraphs earlier. If intrinsic value is to be rejected as problematic or intractable then, it is urged, we must appeal solely to instrumental value, considered as value that is "dependent" on valuers. And Justus et al. claim that such values alone can serve our needs. ${ }^{23}$ Examples of such efficacious instrumental values are said to include: aesthetic value; ecological value; the value of ecosystem services; medical, recreational and tourist value; educational value; "existence value" (i.e. the value of a thing's mere existence); and spiritual value. From the perspective of a non-objectivist account of value, e.g. Richard's, any value depends on valuers in some sense. So the issue as to whether these supposedly "instrumental values" are sufficient for conservation decision-making is whether or not such values are sufficient when clearly identified as merely instrumental in the proper sense, i.e. when they are understood as values that things may have, not as ends in themselves, but as a means to some further end. The ultimate ends typically assumed, of course, are our self-interested ends, our perceived advantage (it is, after all, the human chauvinist that Richard's intrinsic value theory is targeting). In this case, the values are instrumental in the proper sense only if they are identified as the value they have for us (not simply the value they have that depends on us).

To be clear then, the aforementioned values are instrumental only if understood as follows. Ecological value is not merely what is taken to be ecologically valuable by us, but what is ecologically valuable for us; existence value is not merely what is taken to be the value of a thing's existence by us, but the value of a thing's existence for us; and so on. Thus understood, it is far from clear that instrumental value (properly understood) is sufficient. A species' existence (for example) might conceivably have no value for us - it might conceivably not advantage us in any way - though we might value its existing. Its existence may be of no instrumental value to us yet we value it nonetheless. (Of course, if we derive satisfaction from the maintenance of this existence value through species conservation then the thing in question might also have instrumental value, but this consequent value should not be confused with the basis for its conservation, its intrinsic value.) Only by equivocating between its having existence value for us

\footnotetext{
${ }^{23}$ See p. 188.
}

Australasian Journal of Logic (15:2) 2018 Article no. 4.1 
and its existence being valued by us can it be claimed that this latter value can be accounted for within a purely "instrumental" moral framework. And it is this latter value, it seems, that defenders of a purely instrumental account are suggesting can (contra claims by intrinsic value theorists) be accommodated.

Thus we see that: (i) the problems that are said to beset intrinsic value in conservation decision-making are overstated; and (ii) the supposed ability of instrumental value to account for the full range of value considerations needed in conservation decision-making is overestimated. Intrinsic value, properly understood, is both available and needed. There is every reason then to agree with key proponents of the inclusion of the intrinsic value of nonhuman biota in conservation decision-making.

\section{Acknowledgements}

I would like to thank Roger Lamb for the many delightful days spent discussing Richard's philosophy, and for help in removing some of the infelicities that would otherwise have appeared here.

\section{References}

Elliot R. (1997), Faking Nature: the Ethics of Environmental Restoration, Routledge: London.

Justus, J., Colyvan, M., Regan, H. and Macquire, L. (2009), 'Buying in to conservation: Intrinsic versus instrumental value', Trends in Ecology and Evolution 24: 187-191.

Justus, J., Colyvan, M., Regan, H. and Macquire, L. (2009), 'Response to Sagoff', Trends in Ecology and Evolution 24: 644.

Leopold, A. (1949), The Sand County Almanac, Oxford University Press: New York.

Macquire, L. and Justus, J. (2008), 'Why intrinsic value is a poor basis for conservation decisions', Bioscience 58: 910-911.

McCauley, D.J. (2006), 'Selling out on nature', Nature 443: 27-28.

Moore, G.E. (1903), Principia Ethica, Cambridge University Press.

Muir, J. (1916), A Thousand-Mile Walk to the Gulf, Houghton Mifflin.

Australasian Journal of Logic (15:2) 2018 Article no. 4.1 
Naess, A. (1973), 'The shallow and the deep, long-range ecology movement', Inquiry 16: 95-100.

Noss, R. and Cooperrider, A.R. (1994), Saving Nature's Legacy, Island Press.

Routley, R. (1973), 'Is there a need for a new, an environmental, ethic?' Proceedings of the XVth World Congress of Philosophy, Varna, 1: 205-210. Reprinted in M Zimmerman et al. (eds) (1993), Environmental Philosophy: From Animal Rights to Radical Ecology, Prentice Hall, pp.12-21.

Routley, R. and Routley, V. (1979), 'Against the inevitability of human chauvinism', in K.E. Goodpaster and K.M. Sayre (eds), Ethics and Problems of the 21st Century, University of Notre Dame Press, pp. 36-59.

Routley, R. and Routley, V. (1980), 'Human chauvinism and environmental ethics', Environmental Philosophy, Department of Philosophy, Research School of the Social Sciences, Australian National University: Canberra, pp. 96-189.

Routley, V. (1975), “Critical Notice” of Passmore's Man's Responsibility for Nature', Australasian Journal of Philosophy 53: 171-185.

Sagoff, M. (2009), 'Intrinsic value: a reply to Justus et al.', Trends in Ecology and Evolution 24: 643.

Sandler, R. (2012), 'Intrinsic Value, Ecology, and Conservation', Nature Education Knowledge 3: 4.

Singer, P. (1975), Animal Liberation, New York Review/Random House: New York.

Soulé, M.E. (1985), 'What is conservation biology?', Bioscience 35: 727-734.

Sylvan, R. (1985), 'A Critique of Deep Ecology', Discussion Papers in Environmental Philosophy \#12, Department of Philosophy, Research School of the Social Sciences, Australian National University: Canberra. Also in serialised form: 'A Critique of Deep Ecology, Part I', Radical Philosophy 40: 2-12; and 'A Critique of Deep Ecology, Part II', Radical Philosophy 41: 10-22. NB: all references are to the version published in Radical Philosophy.

Sylvan, R. (1996), Philosophical Rehabilitation, working manuscript.

Sylvan, R. and Bennett, D. (1994), The Greening of Ethics, The White Horse Press.

Australasian Journal of Logic (15:2) 2018 Article no. 4.1 